\title{
Plasma plume dynamics, rebound, and recoating of the ablation target in pulsed laser deposition
}

\author{
Alejandro Ojeda-G-P, ${ }^{1}$ Christof W. Schneider, ${ }^{1}$ Max Döbeli, ${ }^{2}$ Thomas Lippert, ${ }^{1,3, a)}$ \\ and Alexander Wokaun ${ }^{1}$ \\ ${ }^{1}$ Paul Scherrer Institut, Energy and Environment Department, 5232 Villigen-PSI, Switzerland \\ ${ }^{2}$ Ion Beam Physics, ETH Zürich, CH-8093 Zürich, Switzerland \\ ${ }^{3}$ Department of Chemistry and Applied Biosciences, Laboratory of Inorganic Chemistry, ETH Zürich, \\ CH-8093 Zürich, Switzerland
}

(Received 30 May 2016; accepted 23 March 2017; published online 7 April 2017)

\begin{abstract}
The effects of the type of background gas and pressure on the spatial distributions of plume species have been investigated by time and space resolved imaging in vacuum, $1 \times 10^{-2}$ mbar and $1 \times 10^{-1}$ mbar $\mathrm{O}_{2}$ and Ar. The ablation of $\mathrm{La}_{0.4} \mathrm{Ca}_{0.6} \mathrm{MnO}_{3}$ in vacuum shows dissimilar arrival times for the different neutral species and a backscattering of the impinging species from the substrate. At $1 \times 10^{-2}$ mbar, a species-dependent plume splitting appears and preferential scattering of the lighter elements is detected generating a cation off-stoichiometry along the plume axis. In addition at $1 \times 10^{-1}$ mbar the plume expansion in this relatively high pressure traps a portion of the background gas against the substrate holder, thereby creating a transient high local pressure with remarkable effects once the plume reaches the substrate. In an Ar background, a rebound wave is seen, which travels backwards and recoats/contaminates the target with a different composition than the original target. In $\mathrm{O}_{2}$, in addition to the rebound, a long-lived volume of excited species is created, which consists mainly of $\mathrm{LaO}$ I. The rebound has important effects on the film composition and is background gas dependent. The same effects are also detected during Ag ablation and are probably valid for most target materials. Published by AIP Publishing.
\end{abstract}

[http://dx.doi.org/10.1063/1.4979780]

\section{INTRODUCTION}

Pulsed laser deposition (PLD) is a very versatile deposition technique that remains unchallenged when attempting the deposition of well-defined thin films with complex stoichiometries. It is indeed the preferred choice when growing functional films of multi-element oxides and has been a critical contributor to material science developments since 1987 in a wide range of fields, from superconductivity, to electrocatalysis or ferroelectricity. ${ }^{1-3}$

In most of those cases, the film composition is often fundamental to achieve the desired properties, and although it is commonly assumed that in PLD a congruent composition transfer from target to film takes place, this is not necessarily the case. Often, it is difficult to find suitable process parameters or users resort to targets containing an excess of a certain element(s) to achieve the desired film compositions. ${ }^{4}$ The causes for such compositional deviations are a multitude of processes that are reviewed in Ref. 5 and which can be divided into three main areas: target, plume, and substrate effects.

Concerning the plume effects, there have been numerous publications investigating its fundamentals. ${ }^{6-10}$ For instance, Canulescu et al. ${ }^{7}$ explored the effects of the background gas pressure on the ablation of $\mathrm{LiMn}_{2} \mathrm{O}_{4}$ by spectrally resolved plume imaging, confirming the mass dependency of the cation off-stoichiometry in the plume. Likewise, Sambri et al.

\footnotetext{
${ }^{\text {a) }}$ Author to whom correspondence should be addressed. Electronic mail: thomas.lippert@psi.ch. Tel.: +41563104076.
}

for the deposition of $\mathrm{LaGaO}_{3}{ }^{8}$ Progress on its modelling has also been reported by Packwood et al. ${ }^{9}$ who used experimental data from Ref. 11 and developed an analytical model of a collision-induced plume expansion that matches the film $\mathrm{Li}$ deficiencies with increased oxygen pressure. However, the most surprising findings concerning plume effects involve its interaction with the substrate. Geohegan et al. ${ }^{12}$ reported an emission in the near substrate region lasting a few $\mu$ s formed by the interactions of incoming and substrate reflected fluxes from pyrolytic carbon ablation in vacuum. Voevodin et al. ${ }^{13}$ showed a similar excitation near the substrate for $\mathrm{Zr}$ I in $\mathrm{Ar}$ from yttria stabilized zirconia ablation.

In our previous research, we used analytical methods to determine the film composition, i.e., Rutherford backscattering spectrometry (RBS) and to explore the effects of the background gas pressure, ${ }^{14}$ angular location or the laser spot geometry ${ }^{15}$ on film composition, detecting changes in composition of up to $\sim 30 \%$ with respect to the target. Furthermore, in a recent study ${ }^{16}$ we explored the influence of the target mass-ratios by depositing films with 5 relevant multi-element perovskite materials: $\mathrm{BaTiO}_{3}, \mathrm{CaTiO}_{3}, \mathrm{La}_{0.4} \mathrm{Ca}_{0.6} \mathrm{MnO}_{3}$, $\mathrm{EuAlO}_{3}$, and $\mathrm{LiMn}_{2} \mathrm{O}_{4}$. A relationship was found between target mass-ratios and compositional deviations, which can lead to deviations of up to $70 \%$ for large mass-ratios, e.g., $\mathrm{Mn} / \mathrm{Li}$, in certain pressure regimes.

In this study, we focus on another of the compositional changes: the interaction of the plasma plume species with the background gas and their interactions with the substrate. We ablate a well-studied perovskite material $\left(\mathrm{La}_{0.4} \mathrm{Ca}_{0.6} \mathrm{MnO}_{3}\right)$ in 
different background gases and pressures, and we use species resolved imaging to study their effects on the plasma plume dynamics. In addition, RBS is used for analyzing the thin film composition of the material deposited at the substrate and target position.

\section{EXPERIMENTAL DETAILS}

The ablation experiments were performed using a KrF excimer laser (Lambda Physik LPX 300, 20 ns pulses, $\lambda=248 \mathrm{~nm}$ ). A mask was used to obtain a rectangular laser spot with dimensions of $1 \mathrm{~mm} \times 1.4 \mathrm{~mm}$ imaged on a ceramic $\mathrm{La}_{0.4} \mathrm{Ca}_{0.6} \mathrm{MnO}_{3}$ cylindrical target whose composition was verified by RBS. To avoid cratering, the target was continuously displaced and rotated. The experiments were carried out with a fluence of $3 \mathrm{~J} / \mathrm{cm}^{2}$ at a repetition rate of $4 \mathrm{~Hz}$. This fluence is in the upper range of the typical values used for perovskite materials $\left(1-3 \mathrm{~J} / \mathrm{cm}^{2}\right)$. It is noteworthy that the reported plasma dynamics change, if the fluence is varied, as it has a direct effect on the kinetic energies of the plasma species. Thus, to observe the same expansion dynamics as reported here for a lower fluence also a lower pressure is required.

Two different background gases were used: $\mathrm{Ar}$ and $\mathrm{O}_{2}$. The former would give an insight into the collisional interactions with limited chemical reactions, while the latter combines both and is a typical gas used in PLD depositions. The experiments were performed in vacuum and at pressures of $1 \times 10^{-2}$ mbar and $1 \times 10^{-1}$ mbar, a pressure range where the mean free path (MFP) is shorter than the target-to-substrate distance. The applied target to substrate distance is $4 \mathrm{~cm}$, and the substrate is mounted on a $2.5 \mathrm{~cm}$ diameter holder. All depositions were performed at nominal room temperature of the substrate. An image of the experimental setup is shown in Fig. 1.

An intensified charge-coupled device (ICCD) "Andor New i-star" DH334T-18-03 was used to record the time evolution of the emitting species of the ablated material. The sensor has a spectral range from 180 to $850 \mathrm{~nm}$, a $1024 \times 1024$ pixel size, and the relationship between image-pixels and physical distance was calculated using the reference distance of $4 \mathrm{~cm}$. The images were recorded for all light passing

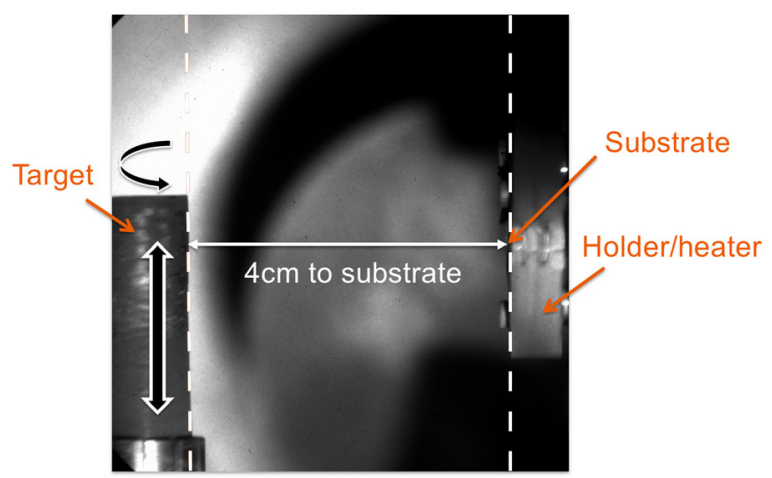

FIG. 1. Image of the experimental setup with the $\mathrm{La}_{0.4} \mathrm{Ca}_{0.6} \mathrm{MnO}_{3}$ target on the left and a substrate $4 \mathrm{~cm}$ away on the right hand side. The substrate is mounted on an un-heated substrate-holder. The image was captured using the same ICCD at the same position as for the experiments. through a quartz window $(200 \mathrm{~nm}-1000 \mathrm{~nm})$ or for selected wavelengths using an Acousto-optic tunable filter (AOTF, 400-1000 nm). The AOTF (Brimrose models VA210-0.55$1.0-\mathrm{H}$ and VA210-0.40-0.65-H) has a wavelength resolution of $0.6-3 \mathrm{~nm}$ with a manufacturer certified resolution of $1.3 \mathrm{~nm}$ at $633 \mathrm{~nm}$. In both cases, a 28-300 mm f/3.5-6.3 macro lens was mounted on the ICCD and set at $f / 3.5$ or $f / 5.6$ for the AOTF measurements.

The camera was triggered externally by the laser pulse using a photo-diode. The on-board digital delay generator was used for gating the image intensifier and increasing timedelays were used to capture its time evolution. Typically, a gate width of $5 \mathrm{~ns}$ for the plume expansion below $2.5 \mu$ s and $50 \mathrm{~ns}$ for later times was used, while for the AOTF measurements a gate width of $100 \mathrm{~ns}$ below $2.5 \mu$ s and $1000 \mathrm{~ns}$ for all other measurements was applied. A gain value of 3500 was used for all non-AOTF and 4095 for all AOTF measurements. For each time-frame, an accumulation of 40 images was used to improve the signal to noise ratio.

Plasma chemical interactions were investigated by spectroscopic analyses using a monochromator (Acton research Spectra Pro 500). The light emitted by the plasma plume between the target and the substrate was captured using an achromatic lens $(200-2000 \mathrm{~nm}, f=500 \mathrm{~mm}$ and $50 \mathrm{~mm}$ diameter) directly in front of the quartz window of the PLD chamber and the light was then directed to the monochromator using a set of mirrors. These measurements were triggered by the same photodiode mentioned above and gated using a Princeton Instruments pulse generator (PG-200) with a $200 \mathrm{~ns}$ delay and a gate-width of $10 \mu \mathrm{s}$. An accumulation of 20 measurements per image was used to improve the signal to noise ratio. To improve the wavelength resolution, the measured wavelength range $(550-825 \mathrm{~nm})$ was divided into smaller range measurements, i.e., $\sim 15 \mathrm{~nm}$, using a high resolution grating which were subsequently stitched together. The results for vacuum conditions (Fig. 2) show the high amount of emission lines and the difficulty to identify lines assigned to single species. Some emission lines were identified using Refs. 17 and 18, although the final selection was based on the recommendations from Ref. 18 and are listed in Table I. The applied spectral lines were mostly from neutral (I) rather than ionized states (II). Fig. 2(b) has been included to show that the selected line for $\mathrm{LaO}$ I $(560.25 \mathrm{~nm})$ and the resolution of the AOTF of $0.75 \mathrm{~nm}$ FWHM are appropriate to avoid the overlap with a $\mathrm{Ca} \mathrm{I}$ line $(558.87 \mathrm{~nm})$. For consistency, all measurements are done in one run to keep the same camera alignment. The selected wavelength values were then used for the AOTF measurements to allow the time-resolved imaging of the different species.

In addition, the composition and thickness of several films deposited at the substrate and target position were obtained by RBS with $2 \mathrm{MeV}{ }^{4} \mathrm{He}$ ions. Software from the Ion Beam Physics group at ETH Zurich and the RUMP software $^{19}$ were used for data analysis.

\section{RESULTS AND DISCUSSION}

The plume expansions without spectral resolution in vacuum, $\mathrm{O}_{2}$, and $\mathrm{Ar}$ are shown in Fig. 3, while the position 
(a)

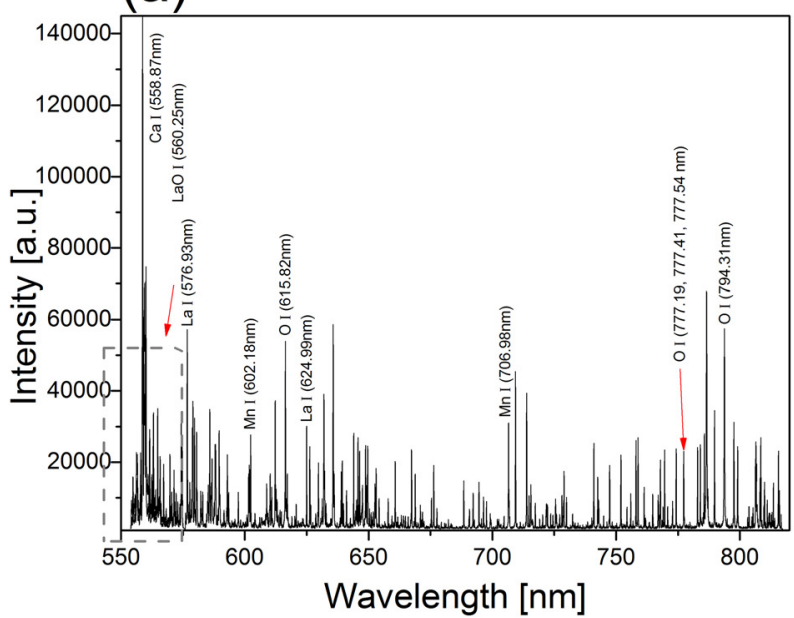

(b)

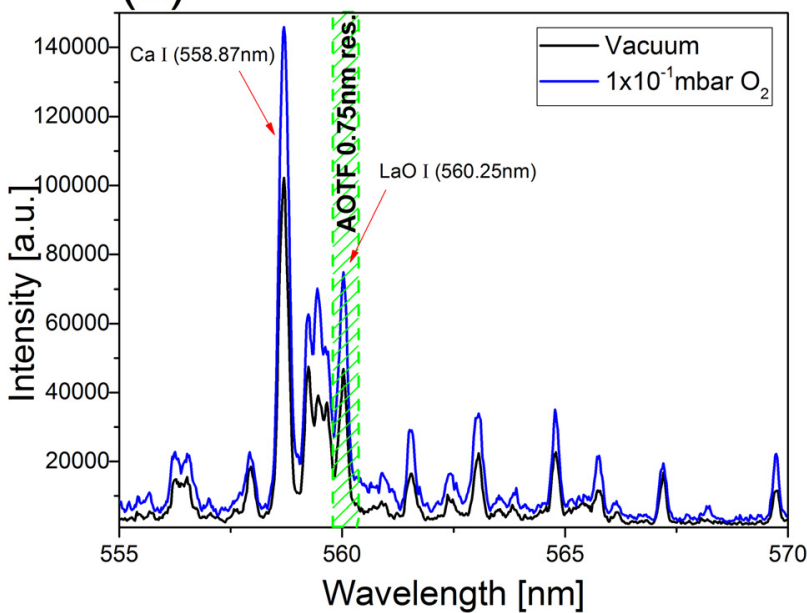

FIG. 2. Emission spectrum for vacuum conditions of $\mathrm{La}_{0.4} \mathrm{Ca}_{0.6} \mathrm{MnO}_{3}$ ablation with a $200 \mathrm{~ns}$ delay and $10 \mu$ s gating from 550 to $830 \mathrm{~nm}$ (a) and for vacuum

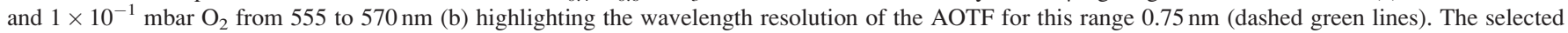
emission wavelengths are highlighted with red arrows. Ar I is not present in the vacuum ablation and was selected directly from the recommendation in Ref. 18 for Ar.

resolved velocities of the plume fronts are plotted in Fig. 4. The velocities were calculated by evaluating the distances travelled by the plume front along the target normal with respect to time of 3 consecutive frames.

There was a $100 \mathrm{~ns}$ delay between frames in the initial stages $<2.5 \mu$ s with a $5 \mathrm{~ns}$ gating, and $1000 \mathrm{~ns}$ delay and a $50 \mathrm{~ns}$ gating above $2.5 \mu \mathrm{s}$. The velocities between the gating change were not calculated nor plotted. The used lens $(f$-number) was the same for all these measurements. Vacuum presents the fastest expansion with the plasma reaching the substrate in less than $1.4 \mu$ s corresponding to a velocity of $\sim 30,000 \mathrm{~m} / \mathrm{s}$ and with an acceleration in its initial stages which is not yet understood (Fig. 4). After $\sim 2 \mu \mathrm{s}$, the plume front is progressively deformed by what seems to be a rebound of the highly energetic species hitting the substrateholder, which is highlighted with a dashed curve at $7 \mu \mathrm{s}$ in Fig. 3 and which is also noticeable in the velocity profile from Fig. 4. If the substrate holder is removed, this curved deformation of the plasma plume does not appear and the plasma expands well beyond the recorded frame (Fig. 5 in vacuum).

At $1 \times 10^{-2}$ mbar, both $\mathrm{O}_{2}$ and Ar background gases exert a decelerating effect on the plasma expansion and the plume dynamics are clearly different for both gases. The plume expansion in $\mathrm{O}_{2}$ is more hemispherical with a stronger emission intensity above $2 \mu \mathrm{s}$ and longer lifetime than in

TABLE I. Used emission wavelengths of $\mathrm{LaO}, \mathrm{Mn}, \mathrm{La}, \mathrm{O}$, and $\mathrm{Ar}$ by either arc, spark, or discharge excitation. ${ }^{17,18}$ Remark: intensities are rough indicators as different observers use different scales and excitation sources.

\begin{tabular}{lccc}
\hline \hline Specie & State & Emission wavelength [nm] & Intensity \\
\hline $\mathrm{LaO}$ & $\mathrm{I}$ & 560.25 & 110 \\
$\mathrm{Mn}$ & $\mathrm{I}$ & 602.18 & 290 \\
$\mathrm{La}$ & $\mathrm{I}$ & 624.993 & 720 \\
$\mathrm{O}$ & $\mathrm{I}$ & 777.54 & 870 \\
$\mathrm{O}$ & $\mathrm{I}$ & 777.41 & 810 \\
$\mathrm{O}$ & $\mathrm{I}$ & 777.19 & 750 \\
$\mathrm{Ar}$ & $\mathrm{I}$ & 811.531 & 35000 \\
\hline \hline
\end{tabular}

vacuum. In Ar, the plume is more narrow with excitations mostly taking place at the plume front. The excitation intensity is also decreasing faster than in vacuum, probably due to a quenching process by the annihilation of the excited state species. ${ }^{20}$ It is noteworthy that the decaying emission intensities for the different pressures and gases overlap with each other during the initial $2 \mu$ s (Fig. 6(a)), after which comparatively higher intensities are observed in $\mathrm{O}_{2}$, although still small compared to higher pressures.

A plume splitting, i.e., the separation of the plasma plume into a fast and a slow component, ${ }^{12}$ is visible at $1 \mu \mathrm{s}$ and already at $1 \times 10^{-2}$ mbar it is noticeable that Ar has a higher stopping ability than $\mathrm{O}_{2}$. This is a consequence of the different masses $\left(\mathrm{O}_{2}=32\right.$ vs. $\left.\mathrm{Ar}=40\right)$ and the different van der Waals volumes. The molecular volume of $\mathrm{O}_{2}$ is $23.013 \AA^{3}$, which has been calculated using the van der Waals radius of $1.52 \AA$ and an interatomic distance of $1.2074 \AA{ }^{17,21}$ while the atomic volume of Ar is $27.83 \AA^{3}$ for the van der Waals radius of $1.88 \AA{ }^{17}$ For both gases, at this pressure the rebound of the plasma from the substrate, seen in vacuum (Fig. 3), is not visible anymore, as the excited species do not reveal any change in direction and continue to arrive at the substrate well beyond $10 \mu \mathrm{s}$. This is probably due to the kinetic energy reduction of the plasma species from collisions with the background gas species.

At $1 \times 10^{-1}$ mbar, the expansion dynamics reveal a pronounced change. The plume is completely confined and expands with decreasing velocities (Fig. 4), with times of arrival at the substrate increasing by one order of magnitude to $t_{\mathrm{O} 2}=13 \mu \mathrm{s}$ and $t_{\mathrm{Ar}}=17 \mu \mathrm{s}$. The emission intensities are also higher by one order of magnitude (Fig. 6) and a plume splitting cannot be observed, while strong excitations are visible at the plasma front. The plume expansion in an $\mathrm{O}_{2}$ background shows a clear volume of excited species just above the substrate that lasts for more than $30 \mu$ s and covers in its final stages $\sim 2 \mathrm{~cm}$ (Fig. 3, $t=39 \mu \mathrm{s}$ ). While in Ar the plume shows a sharper plume front, but expands slower (Fig. 4) and, most surprisingly, reveals a pronounced rebound once it 
Time resolved plasma imaging
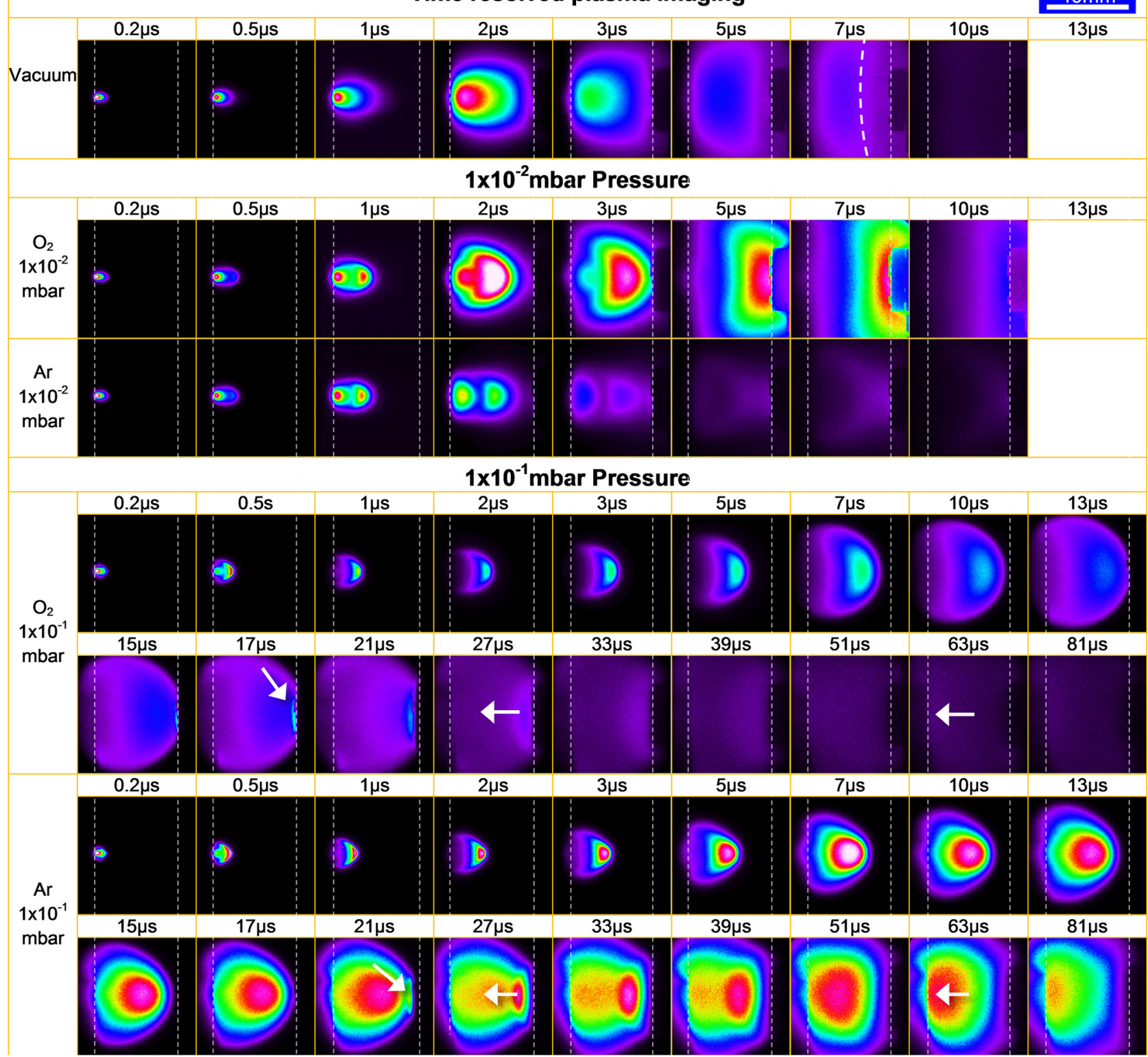

FIG. 3. ICCD time resolved plasma images without AOTF for an ablation in vacuum, $1 \times 10^{-2}$ mbar and $1 \times 10^{-1}$ mbar for $\mathrm{O}_{2}$ and Ar background gases without substrate heating. The plume expands from the ablated target on the left to the substrate on the right (marked with dashed lines). The rebound in vacuum is highlighted with a dashed curve at $7 \mu$ s that follows the border of the compressed plasma. The re-excitation effect in $\mathrm{O}_{2}$ and the rebound effect in Ar are both highlighted with inclined arrows at $17 \mu \mathrm{s}$ and $21 \mu \mathrm{s}$, respectively, while the rebound direction $(t=27 \mu \mathrm{s})$ and the impingement on the ablated target $(t=63 \mu \mathrm{s})$ are marked with horizontal arrows. More detailed images of the rebound in $\mathrm{O}_{2}$ background gas are provided in the supplementary material Fig. S1. The intensity scales are the same for each independent time frame for vacuum, $1 \times 10^{-2} \mathrm{mbar} \mathrm{O}_{2}$ and $1 \times 10^{-2} \mathrm{mbar} \mathrm{Ar}$, while $1 \times 10^{-1} \mathrm{mbar} \mathrm{O}_{2}$ and $1 \times 10^{-1} \mathrm{mbar} \mathrm{Ar}^{-}$ share a separate time-frame scale (due to their much higher intensities).

approaches the substrate (marked with inclined arrows in Fig. 3 at $t=21 \mu \mathrm{s}$ ). A rebound phase that travels all the way back to the target is clearly visible, this rebound phase recoats the target which is observed and marked with an arrow at $t=63 \mu \mathrm{s}$. It is very likely that the composition of the rebounded plasma plume is not the same as the target, as there are different masses and scattering cross sections involved and one can infer that it will modify the target's original composition like other known processes, ${ }^{2}$ e.g., the elemental surface segregation upon cumulative laser irradiation. This is explored in detail below.

A similar emission in the near substrate region, lasting a few $\mu$ s, has been previously reported by other groups. In vacuum for the interactions of incoming and reflected fluxes from pyrolytic carbon ablation ${ }^{12}$ and for a Zr I excitation in Ar from yttria stabilized zirconia ablation. ${ }^{13}$ Although graphite is a very special PLD target, not comparable to oxides, while for yttria stabilized zirconia the experimental pressure was too low to provide pronounced interactions with the expanding plume as at $1 \times 10^{-3} \mathrm{mbar}$ Ar the MFP is $\sim 180 \mathrm{~mm}$ compared to the $60 \mathrm{~mm}$ target-tosubstrate distance. It is also not possible to judge if the emission intensity increased with respect to the previous time-frames.

In our experiments, both arrival effects are visible in the maximum intensities vs. time chart (Fig. 6(b)) and a detailed view of those effects is shown in Fig. 7. The strong excitation for the deposition in $\mathrm{O}_{2}$ background takes place 


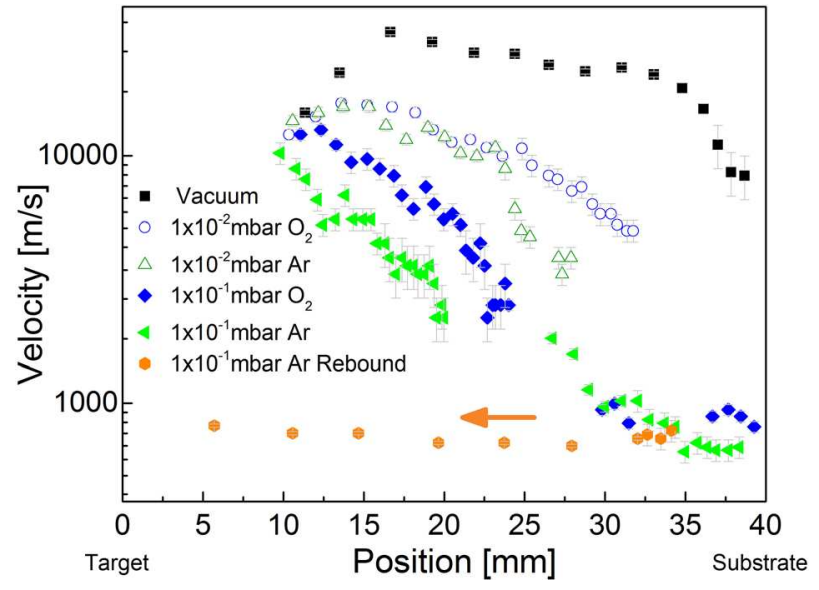

FIG. 4. Position resolved velocities of the plume front along the target normal for different background gases and pressures. The rebound velocity direction has been highlighted using an arrow. The velocities in the first $10 \mathrm{~mm}(\mathrm{t}<100 \mathrm{~ns})$ could not be obtained due to sensor saturation. The time limit of the short-gated measurement (time sequence up to $2.5 \mu \mathrm{s}$ ) limited the detected velocities for $1 \times 10^{-2}$ mbar $\mathrm{O}_{2}$ and $\mathrm{Ar}$, and created a position-gap for the higher pressures (the vacuum expansion fitted in the $2.5 \mu$ s measurement).

just above the substrate/holder and expands with time $1-2 \mathrm{~cm}$ away from the substrate, while in the case of $\mathrm{Ar}$ there is no excitation/light emitting volume on top of the substrate holder. Two $\mathrm{mm}$ before reaching the substrate, the plasma plume is stopped (marked with two dashed lines in Fig. 7(b)) and instants later a rebound wave is seen traveling backwards to the target (observable in Fig. 3 from $21 \mu$ s to $63 \mu \mathrm{s})$. The same experiment using the lighter element Ag showed a $5 \mathrm{~mm}$ gap prior to the subsequent rebound phase. This rebound in $\mathrm{Ar}$ and $\mathrm{O}_{2}$ follows a different mechanism as compared to ablation in vacuum, as the rebound is not caused by the species reflected after interacting with the substrate but by the compressed background gas acting like a spring.

In both background gases, it seems that the rapid expansion of the plasma plume displaces the background gas and a considerable portion of the background gas is trapped at the

(a)

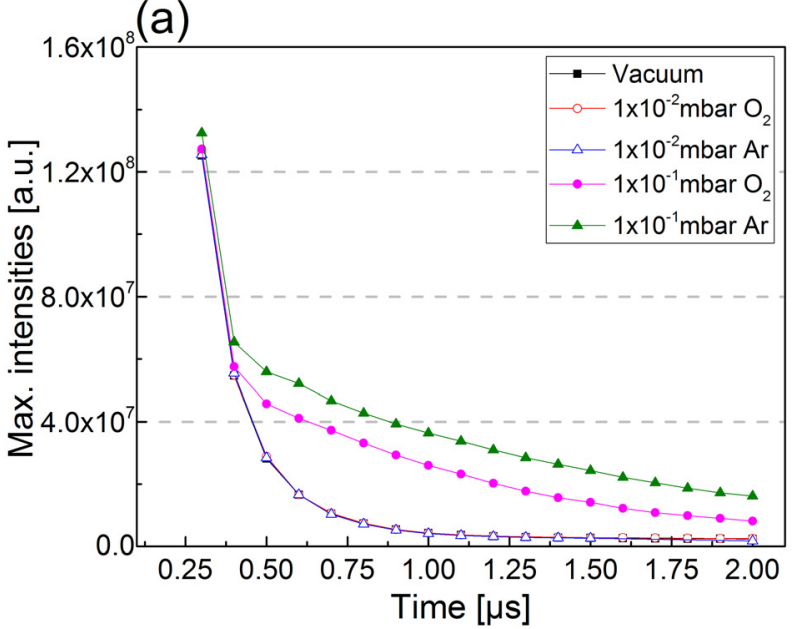

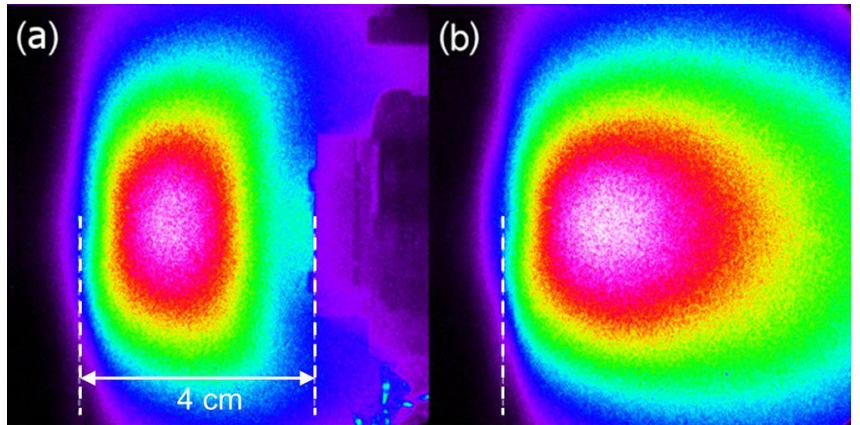

FIG. 5. Image of the plasma expansion in vacuum at $t=5 \mu$ s with the substrate holder present and $4 \mathrm{~cm}$ away from the $\mathrm{La}_{0.4} \mathrm{Ca}_{0.6} \mathrm{MnO}_{3}$ target (a), and without the substrate holder (b). Intensity scales are the same for both plasma images.

front of the substrate holder creating a transient, locally enhanced $\mathrm{O}_{2} / \mathrm{Ar}$ pressure. The same experiment repeated without the substrate holder did not show any of these effects and the plasma expanded beyond $55 \mathrm{~mm}$ before all species are thermalized. This is shown in Fig. 8 for a pressure of $1 \times 10^{-1}$ mbar Ar, where the differences in plasma expansion dynamics without and with a substrate holder for two different time frames are visible. For $\mathrm{O}_{2}$, this locally enhanced pressure is prone to reactions forming new species, while in Ar mainly collisions without reactions are expected. The velocity of the plume is decreased continuously and once the plasma plume is stopped, the compressed gas expands and forces the plume to rebound. Surprisingly, this rebound travels at a constant velocity all the way back to the ablated target with a slightly higher velocity than the arriving species, i.e., $720 \mathrm{~m} / \mathrm{s}$ vs. $650 \mathrm{~m} / \mathrm{s}$ for the arrival velocity, see Fig. 4. In the $\mathrm{O}_{2}$ background gas, a rebound is also observed, but the emitted light is much weaker and eclipsed by the excitation above the substrate (supplementary material Fig. $\mathrm{S} 1$ ). A simple estimation of this transient pressure can be done following Boyle's gas law ( $P V=$ constant), assuming that the temperature and the amount of gas remain unchanged, e.g., for a rapid expansion of the plume. A piston-like compression of a cylindrical volume with a diameter of the substrate holder

(b)

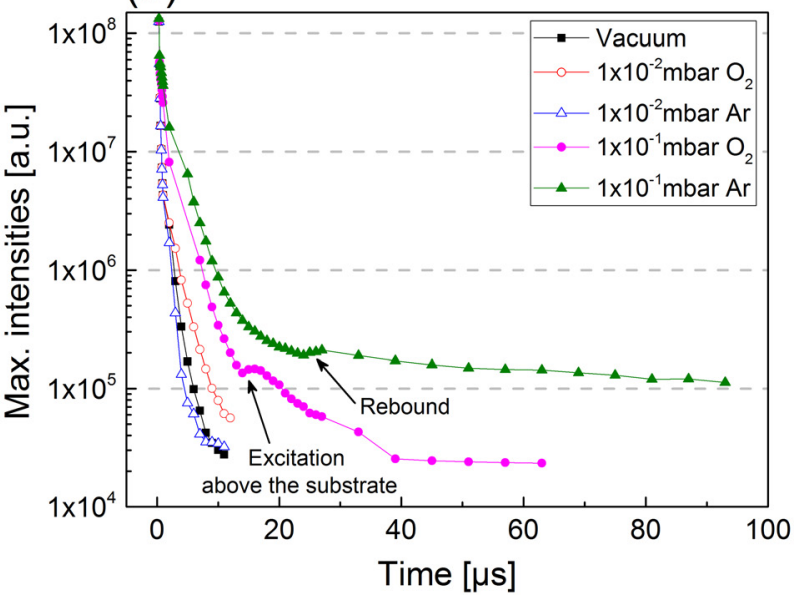

FIG. 6. Evolution with time of the maximum emission intensities for the five different background gas conditions. (a) focuses on the very high intensities during the initial $2 \mu \mathrm{s}$ with a linear intensity scale, while (b) covers up to $100 \mu$ s and uses a logarithmic scale. The signals were partially saturated for the timeframes below $0.3 \mu \mathrm{s}$ and were not included. There is an overlapping of the signals for vacuum, $1 \times 10^{-2} \mathrm{mbar}_{2}$ and $1 \times 10^{-2} \mathrm{mbar}$ Ar up to $2 \mu \mathrm{s}$. 

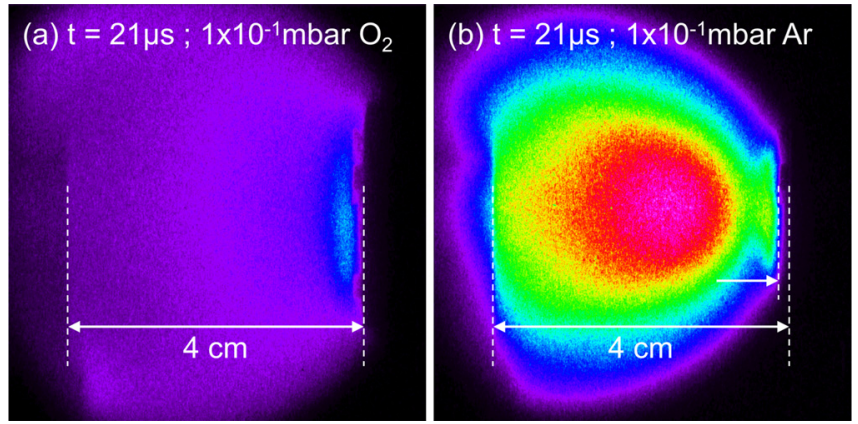

FIG. 7. Plasma plume arrival behavior for $1 \times 10^{-1} \mathrm{mbar}_{2}$ (a) $\mathrm{Ar}$ (b), both at room temperature and with the same intensity scale. The non-emitting area close to the substrate is highlighted in (b) as well as the positions of target and substrate. The intensity scales are the same for both images as well as the exposure time and gain used in the camera measurement.

and a length of $30 \mathrm{~mm}$ to a shorter cylinder of $3 \mathrm{~mm}$ translates to a $\sim 10$ times higher local pressure. This corresponds to a local transient pressure of 1 mbar compared to the 0.1 mbar of the background gas. This locally enhanced pressure is, as far as we are aware of, not implemented in any PLD mathematical model developed to date, ${ }^{22-24}$ but it will most likely have a critical role in deposition rates, chemistry, and dynamics.

The film thickness results reported in Refs. 14 and 15 show that at $1 \times 10^{-1}$ mbar there is a considerable loss of circa $50 \%$ of deposited material compared to a deposition in vacuum (Fig. 9). In vacuum, the thickness profiles are strongly forward peaked, i.e., $\sim 70 \%$ of the deposited material is in the $\pm 40^{\circ}$ angular range, while at $1 \times 10^{-1}$ mbar Ar the peaked profile disappears and a homogenous angular thickness is seen. This has been only assigned to the higher plasma scattering taking place at a pressure of $1 \times 10^{-1} \mathrm{mbar}$, but is

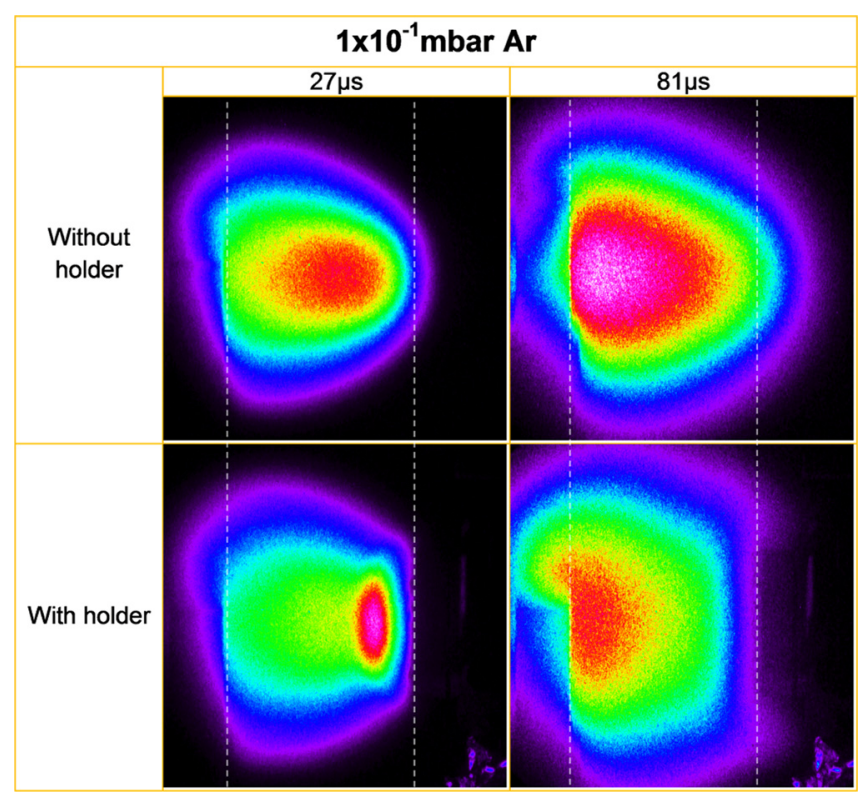

FIG. 8. ICCD time resolved plasma images without AOTF for an ablation at $1 \times 10^{-1}$ mbar Ar without and with the substrate holder for two different time delays, $27 \mu \mathrm{s}$ and $81 \mu \mathrm{s}$. The plume expands from the ablated target on the left to the substrate on the right (marked with dashed lines). The intensity scales are the same for each independent time frame.

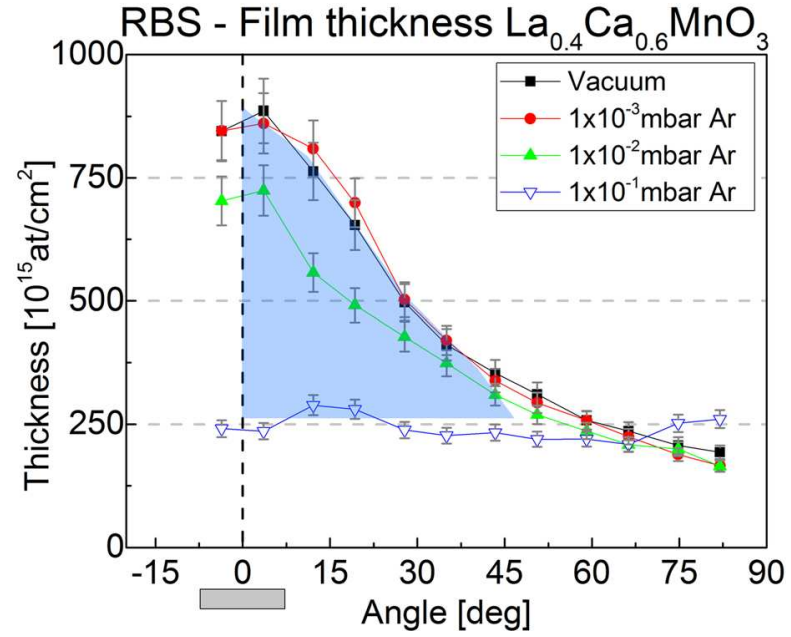

FIG. 9. Angle resolved film thickness profiles of $\mathrm{La}_{0.4} \mathrm{Ca}_{0.6} \mathrm{MnO}_{3}$ for four different Ar background gas pressures from Ref. 14. The forward peak thickness disappears at $1 \times 10^{-1}$ mbar Ar and is highlighted in blue.

also in agreement with the observed rebound of the plume front which disturbs an angular range of $\pm 25^{\circ}$ given by the substrate holder dimensions and target-substrate distance. Thus, a combination of scattering of species over larger angles and rebounding off the substrate might be an additional or alternative explanation for the disappearance of the forward deposition and the presence of a homogenous angular thickness.

\section{A. Time-resolved spatial distribution of species}

Species selective imaging of selected neutral excited state species (Fig. 10) allows a better understanding of the plasma expansion dynamics and of the compositional deviations of the deposited films. In vacuum, the lighter elements have the higher velocities, with $\mathrm{O}$ I showing the fastest expansion $(\sim 30000 \mathrm{~m} / \mathrm{s})$, followed by Mn I $(\sim 23000 \mathrm{~m} / \mathrm{s})$, La I $(\sim 18000 \mathrm{~m} / \mathrm{s})$, and $\mathrm{LaO}$ I $(\sim 17500 \mathrm{~m} / \mathrm{s})$. These velocities were calculated by evaluating the distances travelled by the plume front along the target normal with respect to time of 3 consecutive frames ( 100 ns delay between frames in the initial stages of plume expansion $<2.5 \mu \mathrm{s}$ ) and then calculating the average expansion velocity. The used lens ( $f$-number) was the same for all these measurements. This translates into dissimilar arrival times to the substrate according to mass, i.e., $t_{\text {Oxygen }}=1.2 \mu \mathrm{s}, t_{\mathrm{Mn}}=1.4 \mu \mathrm{s}, t_{\mathrm{La}}=1.6 \mu \mathrm{s}$, and $t_{\mathrm{LaO}}=1.7 \mu \mathrm{s}$. These different arrival times are a direct consequence of the kinetic energies and masses, although the calculated kinetic energies do not exactly match, $\sim 71 \mathrm{eV}$ for $\mathrm{O} \mathrm{I}, \sim 151 \mathrm{eV}$ for $\mathrm{Mn} \mathrm{I}, \sim 227 \mathrm{eV}$ for $\mathrm{La} \mathrm{I}$, and $\sim 246 \mathrm{eV}$ for $\mathrm{LaO}$ I. This is most likely due to dissimilar acceleration dynamics of the species in the plasma plume which will be explored elsewhere. Nevertheless, the dissimilar arrival times and velocities entail complex interactions of incoming and reflected fluxes of species in addition to the possibility of a preferential bouncing mentioned before. It is noteworthy that with the current experimental setup no preferential bouncing could be observed.

At $1 \times 10^{-2}$ mbar, the dissimilar arrival times are counteracted by the background gas (see Fig. 11) where the 


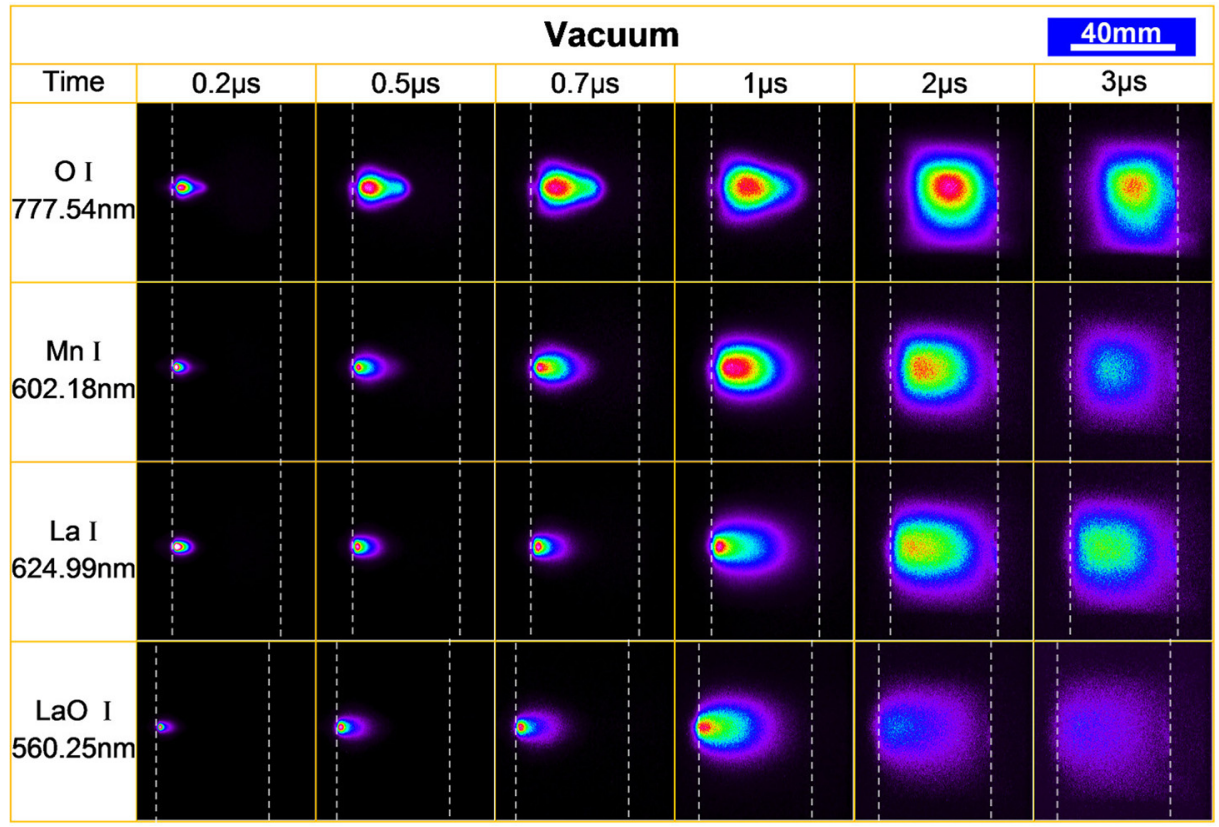

FIG. 10. Vacuum time-resolved images tracing the spatial distribution of the excited species of O I, Mn I, La I, and $\mathrm{LaO}$ I. The plume expands from the ablated target on the left to the substrate on the right (marked with dashed lines). The intensity scales have been normalized to the maximum counts for each image (there is a $\sim 20 \times$ decrease in intensity from 0.2 to $3 \mu \mathrm{s}$ ). Note: due to the use of a different AOTF for $\mathrm{LaO}$ $\mathrm{I}$, the images have a slightly different frame and zoom and the images cannot be directly compared with the other species. lighter elements and those with higher scattering crosssections are preferentially scattered and slowed down by the background gas as compared to heavier species. In both background gases, $\mathrm{O}_{2}$ and $\mathrm{Ar}$, the expansion of $\mathrm{Mn} \mathrm{I}$ is strongly affected (red arrows at $1 \mu$ s in Fig. 11), now being slower than La I and LaO I. Both species keep almost the same velocities up to $1 \mu$ s without major variations as compared to vacuum. The case of $\mathrm{O} \mathrm{I}$ is harder to assess as in an $\mathrm{O}_{2}$ background the images are masked by the addition of $\mathrm{O}_{2}$ excitations from the background gas. An analogous case is observed for the Ar background, where emissions from Ar I are seen. These Ar I emissions are clearly detected and remarkably "arrive" at the substrate in less than $1 \mu \mathrm{s}$. Nevertheless, in the case of an Ar background the expansion velocity of $\mathrm{O} \mathrm{I}$ is clearly reduced as compared to an $\mathrm{O}_{2}$ background. One of the most interesting results is the plumesplitting observed at $2 \mu$ s, highlighted with dashed ellipses for Mn I and La I at $2 \mu$ s in Fig. 11. The Mn I species are almost stopped by the background gas while O I and mostly La I are still able to arrive at the substrate. This can be explained by the MFP which is for $\mathrm{O}$ at $1 \times 10^{-2}$ mbar Ar $54 \mathrm{~mm}$, while only $21 \mathrm{~mm}$ for Mn. The MFP of the different species in Ar background at the applied pressures and at room temperature is calculated using the formula

$$
\lambda=\frac{k_{B} \cdot T}{\sqrt{2} \cdot P \cdot \pi \cdot d_{m}^{2}},
$$

where $T$ is the temperature of the gas, $P$ is the pressure, and $d_{m}=\left(d_{A r}+d_{\text {species }}\right) / 2$ and are summarized in Table II.

This suggests that films produced using these conditions could be Mn deficient, which was already reported in Ref. 14 where a significant decrease of $\sim 13 \%$ of the $\mathrm{Mn} / \mathrm{La}$ ratio was observed.

For a pressure of $1 \times 10^{-1}$ mbar and for both gases (Fig. 12), there are some initial differences in the expansion of the various excited species up to $0.7 \mu \mathrm{s}$. The main difference is the observation of excited $\mathrm{O}$ I species over a larger volume which is more pronounced in the $\mathrm{O}_{2}$ background. However, the differences quickly disappear for times $>0.7 \mu \mathrm{s}$ and a collective front for all recorded species is seen, as indicated by a vertical line at $2 \mu \mathrm{s}$ in Fig. 12. This translates into a simultaneous and very slow arrival of all species to the substrate with a velocity of $\sim 650 \mathrm{~m} / \mathrm{s}$. The $\mathrm{LaO}$ I emission shows a larger area of light emission in $\mathrm{O}_{2}$, caused by more reactions, than in an Ar background, where a much narrower angular distribution is observed. This is probably related to the different scattering cross section of $\mathrm{Ar}$ and $\mathrm{O}_{2}$. In addition, an excitation of Ar I from the background gas is detected well ahead of the other species, which is marked with an inclined arrow at $0.7 \mu \mathrm{s}$ in Fig. 12. This volume of excited Ar I is later disturbed and reshaped by the penetration of the arrow-like expansion of the plume starting at $\sim 1 \mu \mathrm{s}$.

Tracing the spatial distributions of the excited neutral species can also help to understand the observed excitation of the plume upon arrival at the substrate, as seen in $1 \times 10^{-1}$ mbar $\mathrm{O}_{2}$ (Fig. 13). The wavelength resolved images correspond to the different species upon arrival at the substrate. The comparison of the images for La I, LaO I, Mn I, and O I show clearly that the main source of emission is the excitation and/or formation of $\mathrm{LaO}$ I which is also most stable of the different possible metal oxygen species. LaO I is most probably formed upon collisions with the volume of compressed $\mathrm{O}_{2}$ background gas trapped above the substrate holder. This confirms the suggestion that the $\mathrm{O}_{2} / \mathrm{Ar}$ background gases are trapped between the expanding plasma and the substrate holder. This has to the best of our knowledge not been reported and has, as described before, a direct effect on the composition of the deposited thin films. The trapping could even be enhanced by careful engineering of an appropriate 


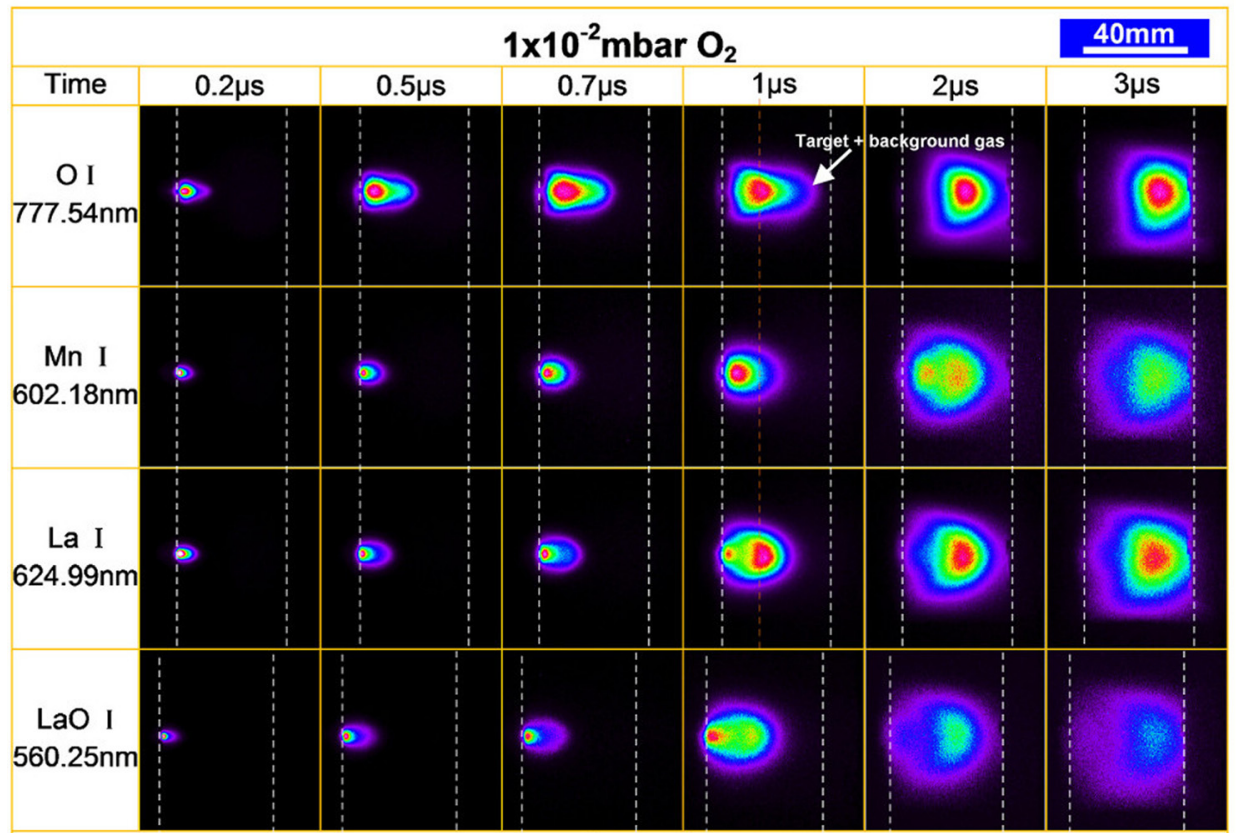

\section{$1 \times 10^{-2} \mathrm{mbar} \mathrm{Ar}$}

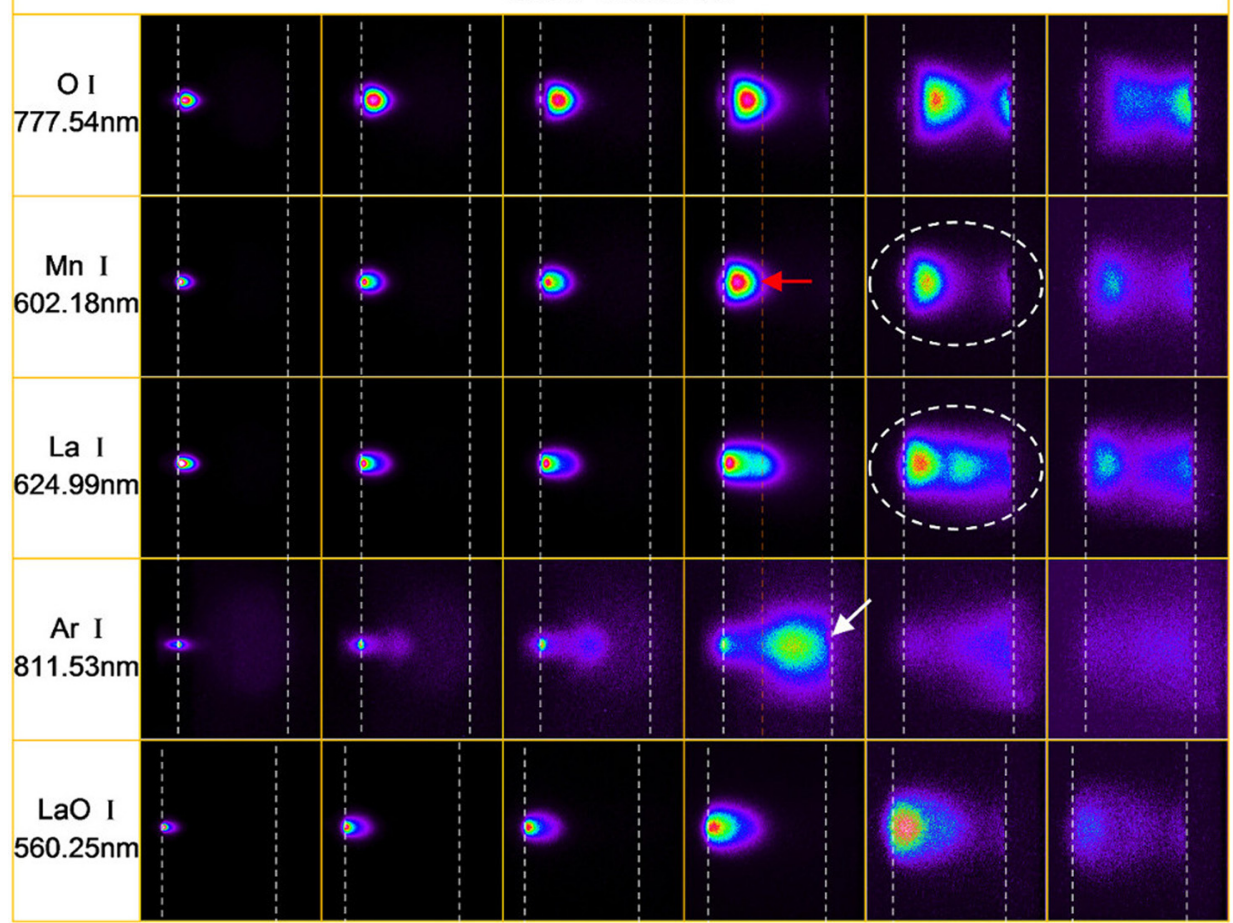

FIG. 11. Time resolved images tracing the spatial distribution of the excited species of O I, Mn I, La I, $\mathrm{LaO}$ I, and $\mathrm{Ar}$ I. Intensity scale has been normalized to the maximum counts for each image (there is a $\sim 10 \times$ decrease in intensity from 0.2 to $3 \mu \mathrm{s}$ ). The $\mathrm{O}$ I excitations in an $\mathrm{O}_{2}$ background are a mixture of excitations from the target and background O I. Note: due to the use of a different $\mathrm{AOTF}$ for $\mathrm{LaO} \mathrm{I}$, the images have a slightly different frame and zoom and the images cannot be directly compared with the other species. substrate holder. For example by using an $\mathrm{O}_{2}$ parabolic

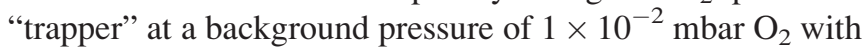
the substrate located at its vertex. Alternatively, an off-axis deposition or the use of a holder with a geometry that reduces the trapping of the background could cancel the effects of background gas trapping. In Ar as background gas, no preferential rebound could be detected in the species resolved images.

TABLE II. MFP values for the different species in Ar gas calculated for different pressures. The target-to-substrate distance was 40 mm, which means that the MFP of the ablated species becomes shorter than the target-to-substrate distance at pressures above $1 \times 10^{-3} \mathrm{mbar}$ Ar (vertical solid line).

\begin{tabular}{|c|c|c|c|c|c|c|}
\hline \multirow[b]{2}{*}{ Element } & \multirow[b]{2}{*}{ Mass (amu) } & \multirow[b]{2}{*}{ Radius (pm) } & \multicolumn{4}{|c|}{ MFP (mm) at different Ar pressures } \\
\hline & & & $1 \times 10^{-6}$ mbar & $1 \times 10^{-3} \mathrm{mbar}$ & $1 \times 10^{-2} \mathrm{mbar}$ & $1 \times 10^{-1} \mathrm{mbar}$ \\
\hline $\mathrm{O}$ & 16 & 60 & 539606 & 540 & 54 & 5.4 \\
\hline $\mathrm{Ca}$ & 40 & 180 & 146985 & 147 & 15 & 1.5 \\
\hline Mn & 54.9 & 140 & 207996 & 208 & 21 & 2.1 \\
\hline $\mathrm{La}$ & 138.9 & 195 & 130875 & 131 & 13 & 1.3 \\
\hline
\end{tabular}



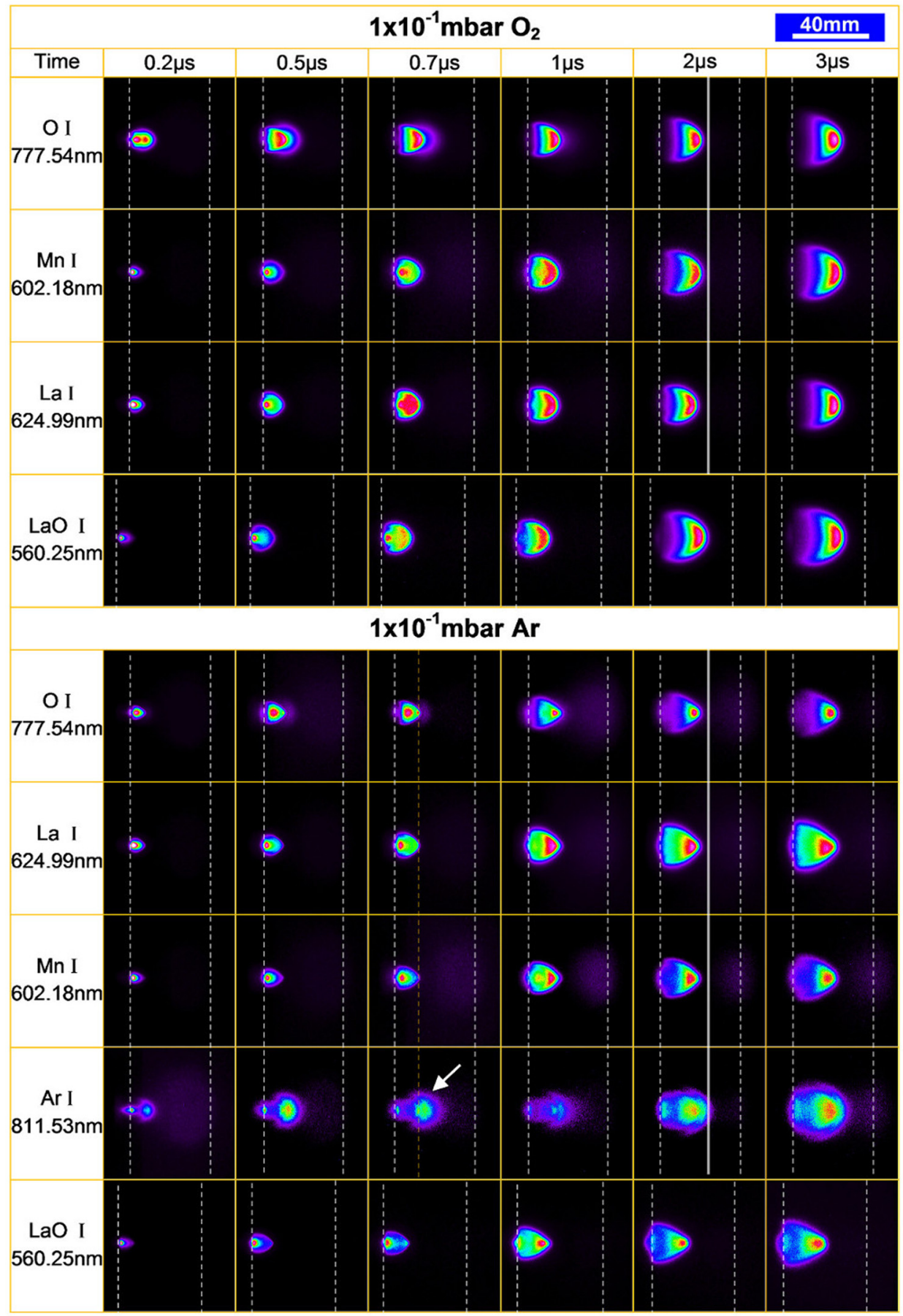

FIG. 12. Time resolved images tracing the spatial distribution of the excited species of O I, Mn I, La I, LaO I, and Ar I. The intensity scale has been normalized to the maximum counts for each image. The excited Ar has been highlighted using an arrow and a dashed line, while the matching fronts of all species $(t=2 \mu \mathrm{s})$ have been marked using a continuous vertical line. Note: due to the use of a different AOTF for LaO I, the images have a slightly different frame and zoom and the images cannot be directly compared with the other species.

\section{B. Thickness and composition of the films deposited from the rebounded material}

Two questions arise when analyzing the rebound effect, i.e., how much material travels back and what is the composition of the back-scattered material? In order to answer those questions, a simple experiment was performed. A substrate was positioned at the typical front location, i.e., where a substrate holder would be positioned, and an additional substrate called "rebound substrate" was placed $1 \mathrm{~mm}$ behind the target, parallel to the substrate holder, and perpendicular to the plasma plume expansion axis to capture the rebounded material. The deposition parameters were kept the same as described in Section II, but a pulse frequency of $3 \mathrm{~Hz}$ was used resulting in a deposition time of 40 min for 7200 pulses. The depositions were carried out at $1 \times 10^{-1}$ mbar $\mathrm{Ar}$ and $\mathrm{O}_{2}$ background gases. Visual inspection of the rebound substrates revealed a film of non-uniform thickness and a clear film discontinuity caused by the shadowing of the rod target in both cases, confirming the significance of the amounts of the rebound material. Normal and rebound films were then measured by RBS and the results are shown in Figs. 14 and 15 for film thickness and film composition, respectively.

In terms of thickness, both frontal deposited films show a homogenous thickness, while the rebound films show a clear directional deposition over the larger area as compared to the normal substrate, with the shadowing of the rod target at the center position. This directionality is in good agreement with 

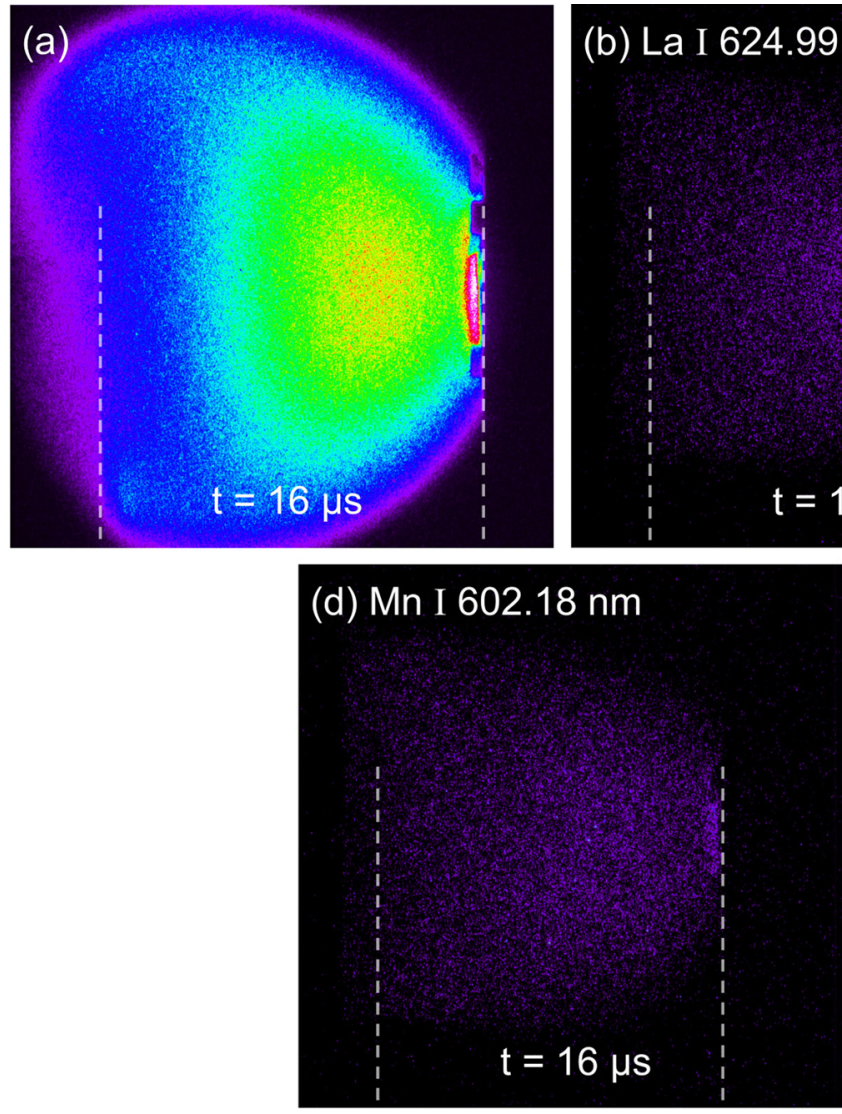
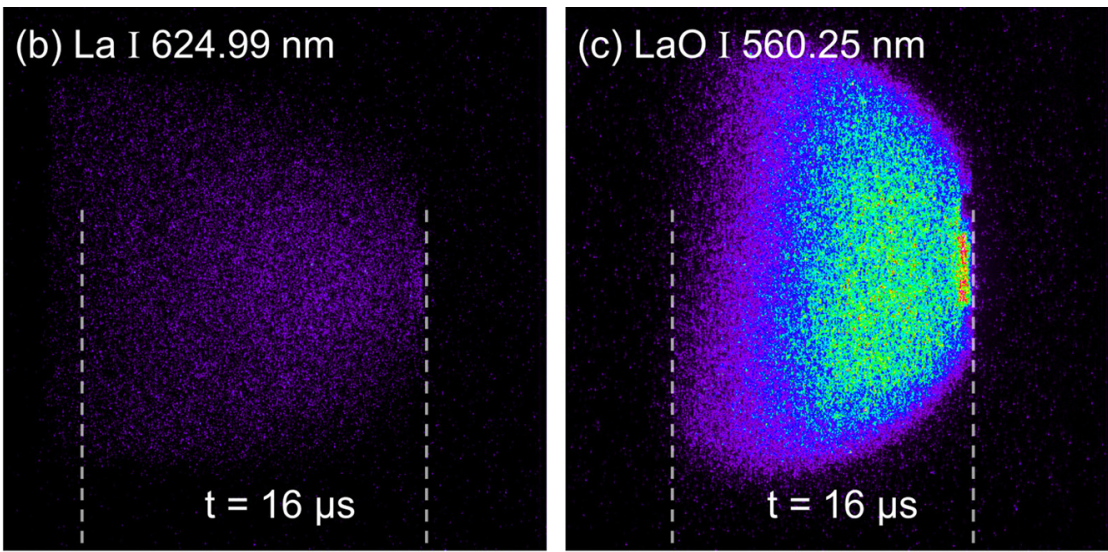

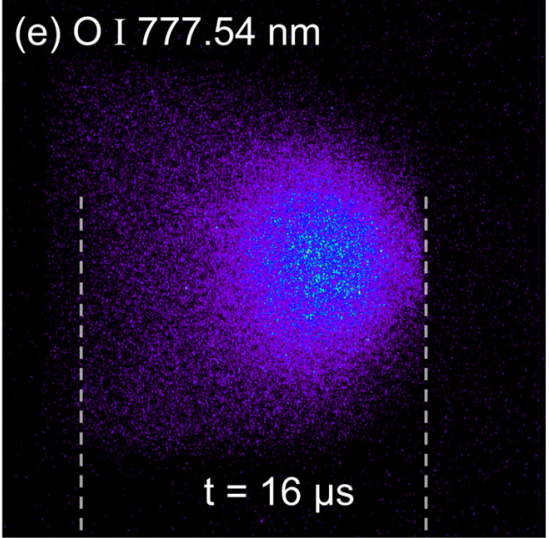

FIG. 13. ICCD images of $\mathrm{La}_{0.4} \mathrm{Ca}_{0.6} \mathrm{MnO}_{3}$ at $1 \times 10^{-1}$ mbar $\mathrm{O}_{2}$ at $t=16 \mu$ s. (a) Image of visible plasma emission (300-1000 nm) showing the high emitting area close to the substrate. Wavelength selected images tracing the spatial distributions of the excited La I (b), LaO I (c), Mn I (d), and O I (e). The intensity scale is the same for all AOTF images, although the transmission efficiency is wavelength dependent and not directly comparable for each image.

the rebound detected in the plasma imaging where the largest amount of material was observed mostly on the substrate to target axis. The film deposited in $\mathrm{O}_{2}$ background is slightly thicker $(\sim 20 \%)$ than the film deposited in $\mathrm{Ar}$, which is due to the lower scattering in $\mathrm{O}_{2}$, while the thicknesses of both rebound films are very similar. The amount of material deposited on the rebound substrate is lower than on the normal substrate holder, but is still significant with values of $65 \%$ for the Ar background and $53 \%$ for the $\mathrm{O}_{2}$ background. In both cases, the cosine-like thickness profile of the rebound material is slightly tilted towards the left side, an indication of a very small misalignment between plasma plume axis,
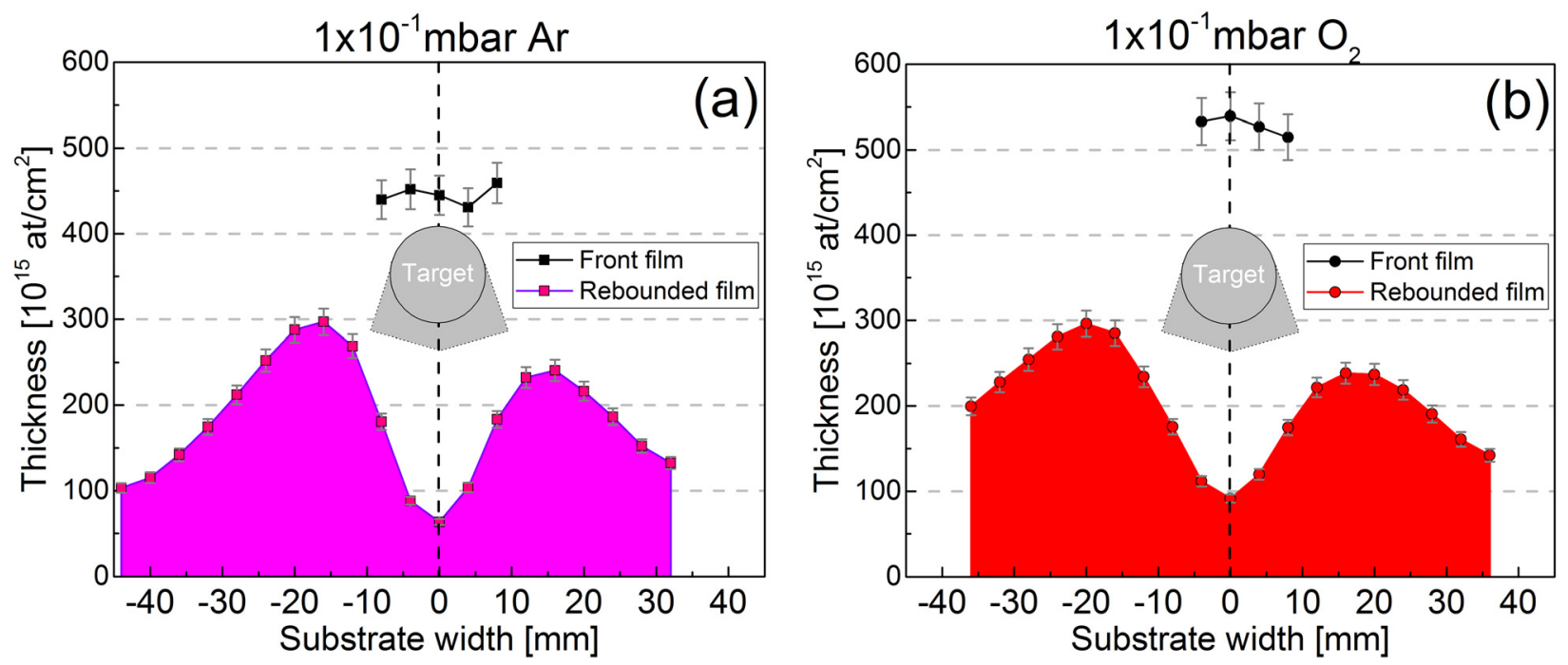

FIG. 14. Frontal and rebound film thickness profiles after $\sim 7200$ pulses for $1 \times 10^{-1} \mathrm{mbar}$ Ar (a) and $\mathrm{O}_{2}$ (b). The target diameter is shown for reference purposes in grey (shadowing effect). The target diameter is shown for reference purposes together with a potential shadow projection of it on the rebound film placed behind. 

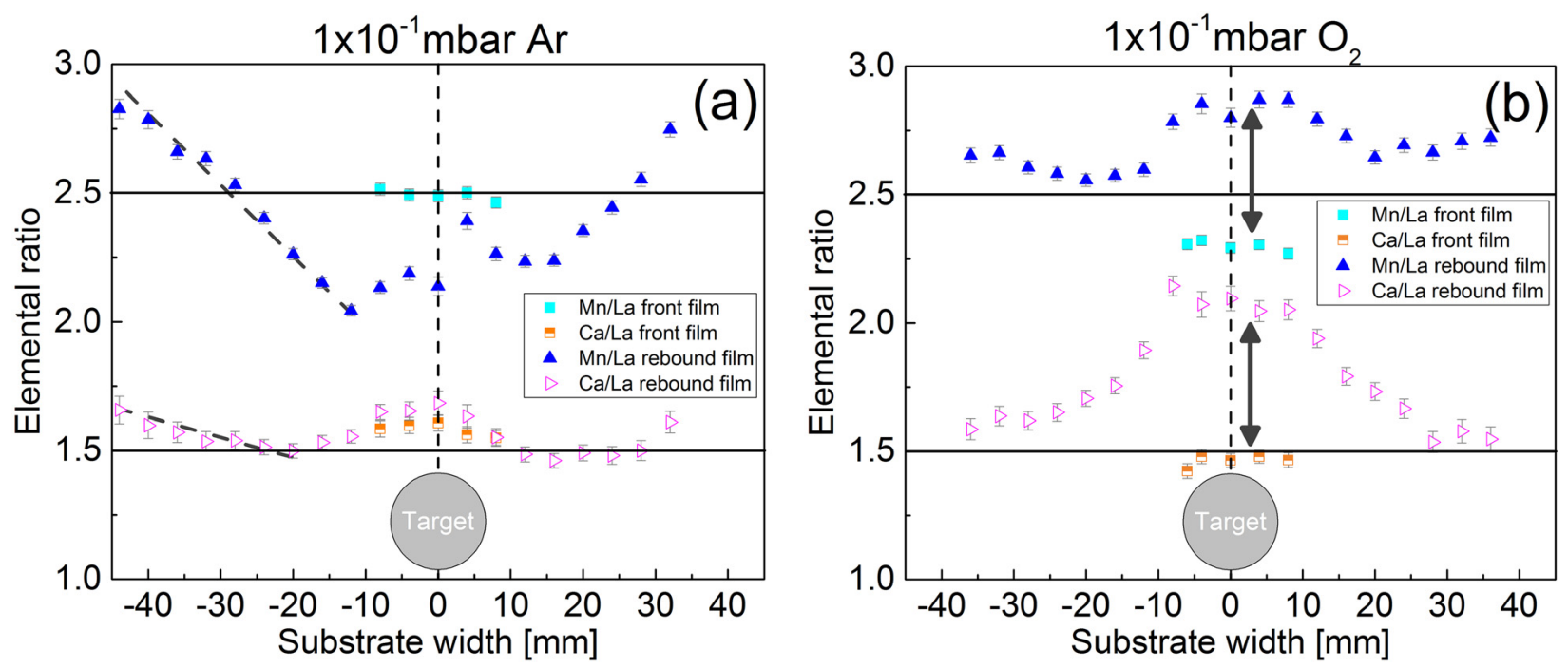

FIG. 15. Frontal and rebound film cation-ratios profiles for $1 \times 10^{-1} \mathrm{mbar} \mathrm{Ar}(\mathrm{a})$ and $\mathrm{O}_{2}$ (b). The target diameter is shown for reference purposes in grey (shadowing effect). The black horizontal lines represent the target elemental ratios. The trends of both elemental ratios have been highlighted with dashed lines as guide to the eye.

substrate holder, and rebound substrate. It is noteworthy that the species travel $\sim 4 \mathrm{~cm}$ in forward direction, rebound on the surface of the substrate holder and travel backwards $\sim 4 \mathrm{~cm}$ plus the added rod target diameter of $\sim 1 \mathrm{~cm}$, totaling to circa $9 \mathrm{~cm}$ in which small misalignments would have strong effects on the precise directionality of the rebound phase. The coating deposited behind the target cannot originate from directional deposition but most likely from diffusion, i.e., a process similar to using a shadow mask.

The analysis of the composition using the elemental ratios of the front films reveals only small variations, i.e., a $\mathrm{Mn} / \mathrm{La}$ ratio similar to the target and an enrichment of the light element $\mathrm{Ca}$, matching the results for Ar background gas from Ref. 15. The rebound film compositions present pronounced changes in the composition which peak at locations close to the "shadowed" area, i.e., the position of the target. The composition of the film in the "shadowed" area is uniform again (without changes in composition). This might evidence that the deposition process for the "shadowed" area is very different to the directional deposition of the rebound film. In an Ar background, the composition of the frontal film and the "shadowed" area of the rebound film reveal similar trends, while in $\mathrm{O}_{2}$ as background a different behavior with diverging ratios above or below the target compositions, which are marked with black arrows in Fig. 15(b), are observed.

The rebound film in the Ar background (Fig. 15(a)) has a $\mathrm{Ca} / \mathrm{La}$ ratio similar to the target and is strongly deficient in $\mathrm{Mn}$, or rich in La, closer to the plume center and shows a gradual enrichment in both light elements with increasing distance from the shadowed area. This trend is kept and at distances above $\pm 25 \mathrm{~mm}$ the film becomes La deficient. The trend has been highlighted with dashed lines in Fig. 15(a). This is most likely due to the center of the plasma plume having the highest concentration of species and it is expected that the numerous collisions, i.e., intra-plume and with the background gas, will preferentially scatter the lighter elements and leave a La rich center of plume.
In the $\mathrm{O}_{2}$ background, the rebound film becomes La deficient in the proximity of the plume axis, as revealed by the increase in the $\mathrm{Mn} / \mathrm{La}$ and $\mathrm{Ca} / \mathrm{La}$ elemental ratios. This La deficiency could be explained by the process observed by emission spectroscopy prior to the rebound i.e., the pronounced emission and formation of $\mathrm{LaO}$ I. The front film composition shows an increase of La by lower $\mathrm{Mn} / \mathrm{La}$ and $\mathrm{Ca} / \mathrm{La}$ ratios suggesting that when La arrives in the form of $\mathrm{LaO}$ at the substrate, more $\mathrm{La}$ is deposited in the front film, and it then becomes "unavailable" in the rebound film. This explains the previously mentioned diverging behavior of the composition, when depositing in an $\mathrm{O}_{2}$ background, between the frontal film and the shadowed area of the rebound film, with the formation of $\mathrm{LaO}$ I above the substrate as a possible cause.

Additional RBS measurements of the rebound film but slightly above the area shadowed by the rod target $(\sim 10 \mathrm{~mm})$ confirm that the frontal film and the rebound film have comparable thicknesses at the central location (Fig. 16(a)). The measurements shown are from the film deposited in an $\mathrm{Ar}$ background as one case of pure collisions with no additional reactions. The composition of the rebound film in this area follows the trend of the lateral sides of the film with a similar $\mathrm{V}$-shaped profile for the Mn/La (Fig. 16(c)) and the $\mathrm{Ca} / \mathrm{La}$ ratios (Fig. 16(d)). However, in both cases, the profiles appear vertically shifted, evidencing a lower concentration of La for the same substrate width position. This has been highlighted using a vertical arrow in Fig. 16(c) and the horizontal arrows in Figs. 16(c) and 16(d) mark the distance where a similar elemental ratio can be found. This is most likely due to the fact that the measured location is $\sim 10 \mathrm{~mm}$ higher than the axis of the plasma plume expansion in which the highest concentration of the heavier La species is expected. Interestingly, the horizontal distance for similar elemental ratios marked by the horizontal arrows is also $\sim 10 \mathrm{~mm}$ for both $\mathrm{Mn} / \mathrm{La}$ and $\mathrm{Ca} / \mathrm{La}$, evidencing a polar distribution of composition on the rebound film with an increased enrichment of light elements with increasing radial distance to the center of the plume. 

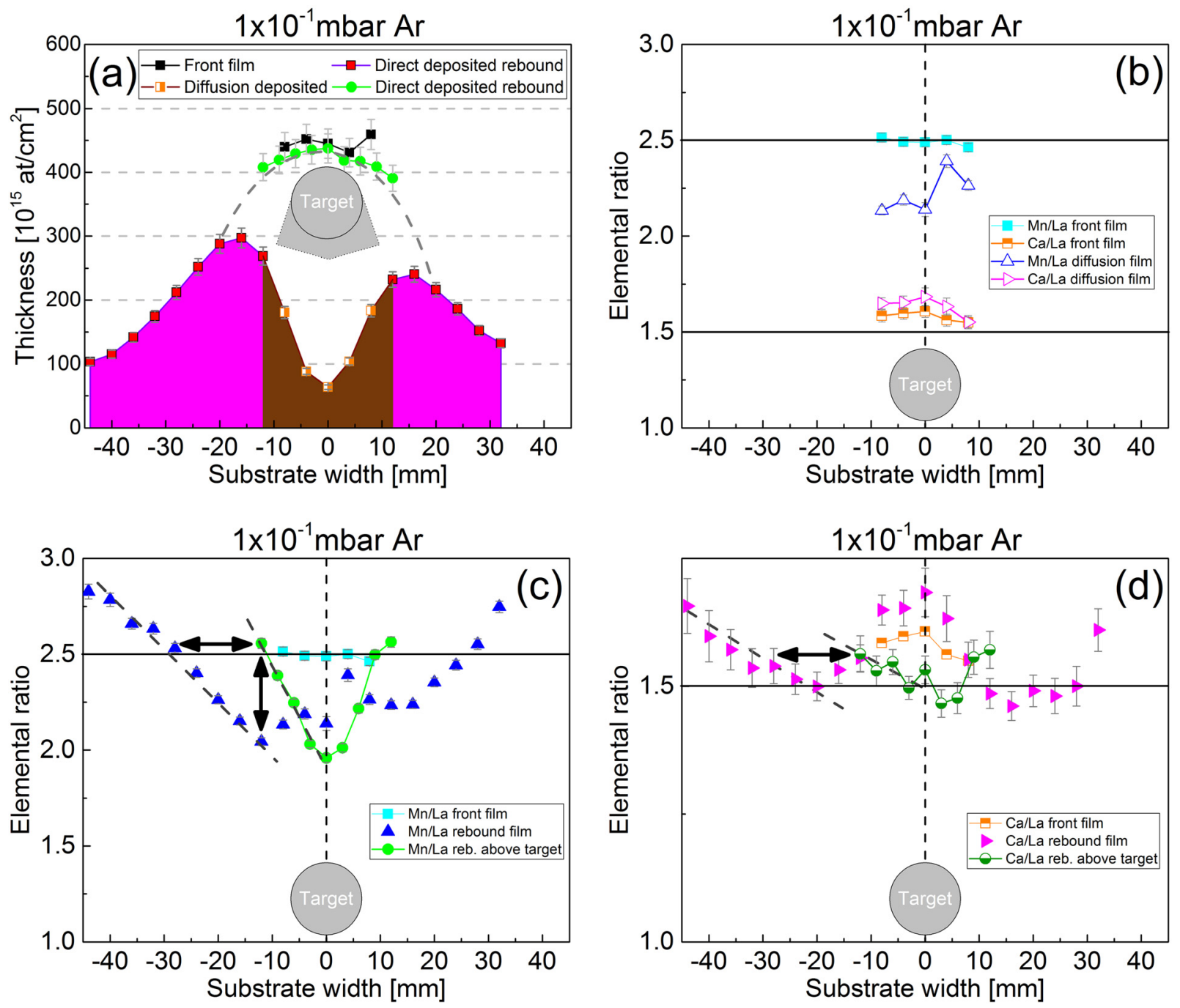

FIG. 16. Rebound film measured by RBS in an area not shadowed by the target, thickness, (a) and cation-ratio profiles (b)-(d) for $1 \times 10^{-1} \mathrm{mbar}$ Ar. The cation-ratios of the shadowed area presented separately for clarity (b) and the results are plotted against the frontal and rebound film measurements already shown before for reference in (c) $\mathrm{Mn} / \mathrm{La}$ and (d) $\mathrm{Ca} / \mathrm{La}$. The black horizontal lines represent the target elemental ratios. The target diameter is shown for reference purposes together with a potential shadow projection of it on the rebound film placed behind (a). The trends of both elemental ratios have been highlighted with dashed lines as guide to the eye.

The pronounced changes in the trends of both $\mathrm{Mn} / \mathrm{La}$ and $\mathrm{Ca} / \mathrm{La}$ ratios that were observed between the nonshadowed and the shadowed areas (Figs. 15(a) and 16(b)) are not present at the same substrate width location just $\sim 10 \mathrm{~mm}$ above the rod target shadowing ( $\pm 15 \mathrm{~mm}$ in Figs. 16(c) and 16(d)). The reduced thickness in the shadowed case and the strong difference in elemental ratios between shadowed and non-shadowed areas of a very similar location suggest that the deposition in the shadowed area is diffusion like, without any direct deposition.

In general, the data show clearly that a significant recoating of the target occurs during the PLD process. A recoating with a different composition than the original target varies depending on the background gas. Furthermore, depositing films in $\mathrm{O}_{2}$ or Ar also affects the film cation content due to the preferential formation of metal oxygen species, as one candidate in $\mathrm{O}_{2}$ containing background gases.

A rough estimation on how the recoating of the target may affect the deposition because of target contamination is given below. The rod target $(\varnothing=12 \mathrm{~mm})$ was ablated over a length of $\sim 20 \mathrm{~mm}$, which corresponds to an ablation area of $\sim 754 \mathrm{~mm}^{2}$. The measured film thickness from tactile profilometry measurements of the rebound material at the peak location is $\sim 100 \mathrm{~nm}$. It can be assumed that due to the rotation of the target, $50 \mathrm{~nm}$ of rebound material will uniformly recoat the ablation area during those $40 \mathrm{~min}$ of deposition. Evidently during those $40 \mathrm{~min}$ ( $\sim 7200$ pulses), the laser will ablate the target material in addition to the rebounded material. Assuming a perfect ablation coverage of the whole area (without overlapping nor spacing), it would take $\sim 540$ shots to return to the first ablation spot, at which $50 \times \frac{540}{7200} \approx 4 \mathrm{~nm}$ of rebounded material would have been re-deposited. From measured ablation rates of $\mathrm{nm} /$ pulse for this material for $3 \mathrm{~J} /$ $\mathrm{cm}^{2}$, it can be estimated that per laser shot an ablation depth of $\sim 21 \mathrm{~nm}$ is achieved. This means that $\sim 20 \%$ of that ablated material would be the rebound material with a composition different to the original target material. A significant value when the film physical properties will be strongly dependant on the composition, even more if it is understood that it is not a steady state as the rebounded material will 
progressively deviate in composition. In the case of a disk target, the continuous exposure of the entire ablation area to the rebound material will enhance the contamination of the target unless the target is small enough that previously ablated locations are often revisited. Following a similar calculation procedure as with the rod target but for a $2 \mathrm{~cm}$ diameter disk target, estimates that $\sim 6.2 \mathrm{~nm}$ of rebounded material would have been re-deposited on the target before revisiting the same ablation spot, this means that $\sim 30 \%$ of the material ablated from the disk target would be rebound material.

\section{CONCLUSIONS}

Time-space and spectral resolved imaging of the laser induced plasma plume from a $\mathrm{La}_{0.4} \mathrm{Ca}_{0.6} \mathrm{MnO}_{3}$ target has been performed to understand the arrival of the film's components and the influence of the background gas and pressure. In vacuum, the inverse relationship between the species' mass and expansion velocity results in dissimilar arrival times at the substrate for the different species. The species arrive with velocities ranging from $18000 \mathrm{~m} / \mathrm{s}$ (La I) up to $30000 \mathrm{~m} / \mathrm{s}$ (O I) and strong rebound effects are detected which deform the plasma plume. This could be one possible source for film composition variations if preferential bouncing would take place.

At $1 \times 10^{-2}$ mbar, the higher velocity of the lighter species is reduced by their preferential scattering with the background gas and a plume splitting is observed. The heavier La I is still able to reach the substrate with similar velocities as in vacuum, while $\mathrm{Mn} \mathrm{I}$ is strongly scattered and almost stopped by the background gas. The overall arriving species at the substrate are La I enriched. This is in agreement with film compositional analyses by $\mathrm{RBS}^{14,15}$ and confirms the suggestions that for certain pressure regimes the enrichment of the heavier elements in the film composition is due to a preferential scattering of the lighter elements.

At $1 \times 10^{-1}$ mbar background pressures of $\mathrm{O}_{2}$ and $\mathrm{Ar}$, all plume species are confined together in a very slowly expanding plume with the same velocity for all species. The data show that the plume expansion at this pressure traps and pressures a portion of the background gas against the substrate holder, creating a transient increased local pressure. In $\mathrm{O}_{2}$ as background, it creates a "long-lived" volume of excited species, mostly $\mathrm{LaO}$ I species, just above the substrate which expands up to $20 \mathrm{~mm}$ from the substrate. This results in an enrichment of $\mathrm{La}$ in the film compared to $\mathrm{Mn}$. In addition, a rebound is seen, while in $\mathrm{Ar}$ as background the rebound wave is clearly observed and travels backwards to the target recoating the target. In both background gases, the thickness of the recoated layer on the target is significant, i.e., $20 \%$ to $30 \%$ of that ablated material per pulse would originate from the rebound material and a steady state will not be reached. More importantly, the composition of the recoated layer is very different compared to the initial target composition and it is background gas and radial dependent. Thus, the complete target will be recoated, and depending on the size of the target, rastering pattern and ablation rate, the recoated layer could make up a substantial part of newly ablated material. This raises questions of how accurately can a film composition be controlled and how significant is the impact on creating defects in the as-grown film due to the unintentional and non-stoichiometric transfer of species. The transient high local pressure above the substrate could be utilized on the other hand to incorporate more oxygen into a film by careful engineering of an appropriate substrate holder as $\mathrm{O}_{2}$ enhances the formation of $\mathrm{LaO}$ which also results in an increased deposition of $\mathrm{La}$ as compared to $\mathrm{Ar}$ as background gas.

\section{SUPPLEMENTARY MATERIAL}

See supplementary material to visualize the rebound in an $\mathrm{O}_{2}$ background (images and animated gifs).

\section{ACKNOWLEDGMENTS}

Financial support from the Paul Scherrer Institut and the Swiss National Science Foundation (SNF/Project 00021_143665) is gratefully acknowledged.

${ }^{1}$ D. Dijkkamp, T. Venkatesan, X. Wu, S. Shaheen, N. Jisrawi, Y. Min-Lee, W. McLean, and M. Croft, Appl. Phys. Lett. 51, 619 (1987).

${ }^{2}$ D. B. Chrisey and G. K. Hubler, Pulsed Laser Deposition of Thin Films (Wiley, New York, 1994), Vol. 1.

${ }^{3}$ T. Venkatesan, J. Phys. D: Appl. Phys. 47, 034001 (2014).

${ }^{4}$ H. M. Christen and G. Eres, J. Phys.: Condens. Matter 20, 264005 (2008).

${ }^{5}$ J. Schou, Appl. Surf. Sci. 255, 5191 (2009).

${ }^{6}$ S. Gurlui, M. Agop, P. Nica, M. Ziskind, and C. Focsa, Phys. Rev. E 78, 026405 (2008).

${ }^{7}$ S. Canulescu, E. L. Papadopoulou, D. Anglos, T. Lippert, C. W. Schneider, and A. Wokaun, J. Appl. Phys. 105, 063107 (2009).

${ }^{8}$ A. Sambri, C. Aruta, E. Di Gennaro, X. Wang, U. S. di Uccio, F. M. Granozio, and S. Amoruso, J. Appl. Phys. 119, 125301 (2016).

${ }^{9}$ D. M. Packwood, S. Shiraki, and T. Hitosugi, Phys. Rev. Lett. 111, 036101 (2013).

${ }^{10}$ S. S. Harilal, J. Appl. Phys. 102, 123306 (2007).

${ }^{11}$ D. O'Mahony, J. Lunney, T. Dumont, S. Canulescu, T. Lippert, and A. Wokaun, Appl. Surf. Sci. 254, 811 (2007).

${ }^{12}$ D. B. Geohegan and A. A. Puretzky, MRS Online Proc. Libr. Arch. 397, 55 (1995).

${ }^{13}$ A. Voevodin, J. Jones, and J. Zabinski, J. Appl. Phys. 88, 1088 (2000).

${ }^{14}$ A. Ojeda-G-P, C. W. Schneider, M. Döbeli, T. Lippert, and A. Wokaun, Appl. Surf. Sci. 336, 150 (2015).

${ }^{15}$ A. Ojeda-G-P, C. W. Schneider, M. Döbeli, T. Lippert, and A. Wokaun, Appl. Surf. Sci. 357(Part B), 2055 (2015).

${ }^{16}$ A. Ojeda-GP, C. W. Schneider, M. Döbeli, T. Lippert, and A. Wokaun, Appl. Surf. Sci. 389, 126 (2016).

${ }^{17}$ W. M. Haynes, CRC Handbook of Chemistry and Physics (CRC Press, 2014).

${ }^{18}$ F. Phelps III, MIT Wavelength Tables. Volume 2. Wavelengths by Element (1982).

${ }^{19}$ L. R. Doolittle, Nucl. Instrum. Methods Phys. Res., Sect. B 15, 227 (1986).

${ }^{20}$ Y. M. Ibrahim, E. H. Alsharaeh, and M. S. El-Shall, J. Phys. Chem. B 108, 3959 (2004).

${ }^{21}$ S. S. Batsanov, Inorg. Mater. 37, 871 (2001).

${ }^{22}$ S. I. Anisimov, B. S. Luk'yanchuk, and A. Luches, Appl. Surf. Sci. 96-98, 24 (1996)

${ }^{23}$ A. Sambri, S. Amoruso, X. Wang, F. M. Granozio, and R. Bruzzese, J. Appl. Phys. 104, 053304 (2008).

${ }^{24}$ D. Marla, U. V. Bhandarkar, and S. S. Joshi, J. Appl. Phys. 109, 021101 (2011). 